\title{
Assisted ejaculation combined with in vitro fertilisation: an effective technique treating male infertility due to spinal cord injury
}

\author{
C Hultling, ${ }^{1}$ R Levi, ${ }^{1}$ L Garoff, ${ }^{2}$ L Nylund, ${ }^{2}$ L Rosenborg, ${ }^{2}$ P Sjöblom, ${ }^{2}$ T Hillensjö ${ }^{2}$ \\ ${ }^{1}$ Spinal Injury Project, Karolinska Institute, S-126 91 Stockholm; ${ }^{2}$ Department of \\ Obstetrics \& Gynecology, Huddinge University Hospital, Stockholm, Sweden.
}

Infertility due to spinal cord injury (SCI) in males has been identified for decades as an area of major concern and techniques for assisted ejaculation are available. There has not been an overall consensus regarding which type of assisted procreation is the most appropriate for these couples. We describe here our experience from a programme based on assisted ejaculation combined with in vitro fertilization (IVF). Twelve couples have been treated so far and altogether 22 cycles with ovum pick-up have been completed. Fertilisation of the oocytes was obtained in 18 of these cycles. The overall oocyte fertilisation rate was $49 \%$. Embryo transfer took place in 17 cycles, leading to seven clinical pregnancies. Four of the pregnancies are delivered or are ongoing, whereas three ended in first trimester spontaneous abortion. Thus our initial experience suggests that assisted ejaculation in combination with IVF is an effective option for these couples.

Keywords: spinal cord injury; male infertility; in vitro fertilisation (IVF); pregnancy.

\section{Introduction}

Each year approximately 150 individuals in Sweden sustain a traumatic spinal cord injury (SCI). Eighty-five percent $(85 \%)$ are males, with a median age at the time of injury of 23 years. ${ }^{1}$ Most had an active sexual life prior to the injury, and, with a large proportion living in stable relationships, it is not surprising that many express a strong desire for fatherhood, SCI causes both erectile and ejaculatory dysfunction, as well as reduced sperm quality. ${ }^{2}$ The resulting subfertility or infertility has received relatively little attention in general and only a few centres have given it proper priority.

One of the founding fathers of modern SCI care, Sir Ludwig Guttmann, did pioneering work in the field of male SCI subfertility. ${ }^{3}$ Later, Brindley devised methods and techniques for vibratory and electrical stimulation in order to enhance ejaculation. ${ }^{4}$ More recently Seager has further refined equipment for electroejaculation. ${ }^{5}$

The methods available for extracting sperm from SCI men have improved, and it can now be estimated that in approximately $80 \%$ of these men it is possible to obtain living sperm. ${ }^{6}$ Sperm recovered in this way, however, have seldom been used in connection with the most advanced methods for assisted procreation. It has been more common to suggest that the patient tries to ejaculate at home and use the sperm for vaginal insemination by means of a catheter or syringe. Alternatively, sperm obtained through assisted ejaculation have been used for intrauterine insemination. ${ }^{7}$ Although such techniques yield pregnancies, it seems to be a rather ineffective and time consuming way to assist these couples to achieve pregnancy. More recently, assisted ejaculation has been used successfully in connection with in vitro fertilisation (IVF). ${ }^{8}$ Since 1991 we have developed a programme for the treatment of male infertility due to SCI, based on assisted ejaculation in combination with IVF. We here report our initial experience. 


\section{Materials and methods}

\section{Patients}

At the Solberga Spinal Cord Injury Project a survey has been done of all persons with traumatic SCI in the greater Stockholm area. The patients were examined by a physician and medical problems in general, and infertility and sexual dysfunction in particular, were recorded. So far about 400 patients have been examined, of whom $85 \%$ are males. Approximately 30 of these males live in stable relationships, are infertile as a result of their injury and express a strong wish for fatherhood. In our pilot study, 12 men with $\mathrm{SCI}$, requiring vibratory- or electrostimulation for ejaculation, were selected. Age, time since injury and basic neurological classification of the study group are described in Table I. Their spouses had regular menstrual cycles and were found to be healthy on routine gynaecological examination. Median age was 34 years (range 27-38). Seven of the women were 0 gravidae, whereas five were I-II gravidae. Three had children of their own from previous marriages. The study was approved by the local ethics committee at the Karolinska Institute.

\section{Procedures}

In order to obtain pituitary down-regulation a GnRH-agonist (nafarelin or buserelin) was administered intranasally starting on cycle day 1 or 21 . For ovarian hyperstimulation, human menopausal gonadotropin (HMG Pergonal $^{\mathrm{R}}$ ) or urinary follicle stimulating hormone (Fertinorm $\mathrm{HP}^{\mathrm{R}}$ ) was injected daily for 10-12 days (150-300 IU/day). Both partners had received prophylactic antibiotic treatment with metronidazol ( $0.5 \mathrm{~g}$ three times daily for 5 days $)$ and doxycycline ( $0.1 \mathrm{~g}$ daily for 7 days) starting at the first day of the HMG treatment. The cycle was monitored by serum estradiol and ovarian ultrasonography. The criteria for administration of human chorionic gonadotropin (hCG, Profasi $\left.{ }^{\mathrm{R}}, 10.000 \mathrm{IU}\right)$ were the presence of at least one follicle greater than $18 \mathrm{~mm}$ in diameter, a continuous rise of estradiol for at least 7-8 days and an endometrial thickness of at least $8 \mathrm{~mm}$. Oocyte retrieval took place 37 hours after the hCG injection and was done by transvaginal ultrasound-guided follicular aspiration. ${ }^{9}$ The oocytes were precultured for 3-4 hours before insemination. Fertilisation was evaluated after 18-20 hours of culture and cleavage stages after 44-48 hours. At embryo transfer, 2 or 3 days after oocyte retrieval a Wallace $^{\mathrm{R}}(\mathrm{H} \mathrm{G}$ Wallace $\mathrm{Ltd}$, Colchester, England) or Frydman ${ }^{\mathrm{R}}$ (Prodimed, Orsay, France) catheter was used. Initially, a maximum of four pre-embryos were transferred to the uterus, but more recently a maximum of two pre-embryos have been transferred, in order to avoid high order multiple pregnancy. When

Table I ASIA classification

\begin{tabular}{lcccccl}
\hline Patient & $\begin{array}{c}\text { Age } \\
\text { (years) }\end{array}$ & $\begin{array}{c}\text { Time since } \\
\text { injury } \\
\text { (years) }\end{array}$ & $\begin{array}{c}\text { Neurological } \\
\text { level }\end{array}$ & $\begin{array}{c}\text { ASIA } \\
\text { impairment } \\
\text { scale }\end{array}$ & $\begin{array}{c}\text { Motor } \\
\text { Index }\end{array}$ & $\begin{array}{l}\text { Neurological } \\
\text { syndrome }\end{array}$ \\
\hline $\mathrm{A}$ & 51 & 33 & $\mathrm{C} 5$ & $\mathrm{C}$ & 43 & Mixed \\
$\mathrm{B}$ & 34 & 4 & $\mathrm{C} 5$ & $\mathrm{D}$ & 51 & Mixed \\
$\mathrm{C}$ & 38 & 13 & $\mathrm{~T} 12$ & $\mathrm{~A}$ & 50 & Conus medullaris \\
$\mathrm{D}$ & 27 & 6 & $\mathrm{~T} 11$ & $\mathrm{~A}$ & 50 & Complete \\
$\mathrm{E}$ & 30 & 11 & $\mathrm{~L} 3$ & $\mathrm{D}$ & 98 & Cauda equina \\
$\mathrm{F}$ & 27 & 7 & $\mathrm{~T} 4$ & $\mathrm{~A}$ & 50 & Complete \\
$\mathrm{G}$ & 39 & 8 & $\mathrm{C} 6$ & $\mathrm{~A}$ & 20 & Complete \\
$\mathrm{H}$ & 40 & 23 & $\mathrm{C} 4$ & $\mathrm{C}$ & 13 & Mixed \\
$\mathrm{I}$ & 37 & 32 & $\mathrm{~T} 10$ & $\mathrm{~A}$ & 50 & Complete \\
$\mathrm{J}$ & 39 & 14 & $\mathrm{~T} 4$ & $\mathrm{~A}$ & 46 & Complete \\
$\mathrm{K}$ & 40 & 15 & $\mathrm{~T} 8$ & $\mathrm{~A}$ & 50 & Complete \\
$\mathrm{L}$ & 37 & 21 & $\mathrm{~T} 6$ & $\mathrm{~A}$ & 50 & Complete \\
\hline
\end{tabular}

${ }^{a}$ penile prosthesis, nonfunctioning. 
available, any remaining pre-embryos of good quality were frozen, using a slow freezing protocol. ${ }^{10}$

In order to elicit ejaculation vibratory stimulation was first tried, if necessary in combination with physostigmine. ${ }^{11}$ If this treatment was ineffective, the second step was transrectal electrostimulation ad modum Seager, ${ }^{5}$ usually under general anaesthesia. Careful monitoring and treatment of blood pressure elevation are necessary in those patients where potentially serious autonomic dysfunction may occur. When needed, a calcium antagonist (nifedepin) was used to counteract autonomic dysreflexia. In order to recover sperm which were ejaculated in the retrograde direction the urinary bladder was washed before the stimulation and fresh HEPES-buffered culture medium was instilled $(20-75 \mathrm{ml})$ in the bladder. The antegrade fraction was collected in a $50 \mathrm{ml}$ test tube and the retrograde fraction was recovered after stimulation. The recovered sperm sample was transferred to the laboratory for preparation through swim-up or Percoll density gradient centrifugation. Sperm motility was stimulated with pentoxyfyllin. Semen was analysed with a Cell Soft (Cryo Resources, New York, USA) computer assisted semen analysis system.

\section{Control material}

The results of IVF in the study group were compared with the results of routine IVF at our unit. The inclusion criteria for IVF at the unit are tubal factor sterility or endo- metriosis and normal semen sample. The same stimulation protocols and procedures as described above were used in this group of women. The study period was January 1992-November 1993.

\section{Results}

On two occasions sperm were extracted by vibratory stimulation; in all other cases transrectal electrostimulation ad modum Seager was required in order to elicit ejaculation. Semen data on the ante- and retrograde fractions are given in Table II. The clinical results of 23 cycles in 12 couples are presented in Table III-V. In 17 of these cycles (10 couples) embryo transfer took place. So far, seven pregnancies have been obtained. In one couple pregnancy was established twice, the first ending in spontaneous abortion and the second ongoing. Of these pregnancies, two have resulted in

Table II Characteristics of semen samples obtained from 12 spinal cord injured men in pilot study

\begin{tabular}{lcc}
\hline & Median & Range \\
\hline Concentration, $10^{6} / \mathrm{ml}$ & 91 & $3.5-202$ \\
$\%$ motile sperm & 11 & $5-57$ \\
Total motile count, $10^{6} / \mathrm{ml}$ & 73 & $11-442$ \\
$\begin{array}{l}\text { Concentration, } 10^{6} / \mathrm{ml} \\
\text { prepared sperm }\end{array}$ & 29.5 & $2.5-2.5$ \\
$\begin{array}{l}\% \text { motile sperm } \\
\text { prepared sperm }\end{array}$ & 27.5 & $0.2-99$ \\
$\begin{array}{l}\text { Total motile count, } 10^{6} / \mathrm{ml} \\
\text { prepared sperm }\end{array}$ & 2 & $0.16-32$ \\
\hline
\end{tabular}

Table III Fertilisation rate in the different couples A-L (\%)

\begin{tabular}{lllcl}
\hline $\mathrm{A}$ & 0 & $4 / 27(15)^{\mathrm{a}}$ & $13 / 27(48)^{\mathrm{a}}$ & \\
$\mathrm{B}$ & $5 / 6(83)$ & $2 / 4(50)$ & $7 / 7(100)^{\mathrm{a}}$ & $3 / 3(100)$ \\
$\mathrm{C}$ & $4 / 16(25)$ & & & \\
$\mathrm{D}$ & 0 & $12 / 17(94)$ & $13 / 14(93)$ \\
$\mathrm{E}$ & $14 / 16(86)$ & & \\
$\mathrm{F}$ & $11 / 14(79)^{\mathrm{a}}$ & & & \\
$\mathrm{G}$ & $7 / 11(64)^{\mathrm{a}}$ & $4 / 6(66)^{\mathrm{a}}$ & & \\
$\mathrm{H}$ & 0 & $6 / 11(55)$ & & \\
$\mathrm{I}$ & $4 / 17(24)$ & & \\
$\mathrm{J}$ & 0 & & \\
$\mathrm{~K}$ & $2 / 3(66)^{\mathrm{a}}$ & & \\
$\mathrm{L}$ & $9 / 11(81)^{\mathrm{a}}$ & & \\
\hline
\end{tabular}

$\mathrm{a}=$ pregnancy. 
Table IV Clinical results

\begin{tabular}{lcc}
\hline & Cycles & Couples \\
\hline No. started & 23 & 12 \\
Ovum pick-up & 22 & 12 \\
Transfer & 17 & 10 \\
Pregnancy & 7 & 6 \\
Spontaneous abortion & 3 & 3 \\
Delivered & 2 & 2 \\
Ongoing & 2 & 2 \\
\hline
\end{tabular}

Table V Fertilisation and cleavage

\begin{tabular}{llc}
\hline & SCI group & $\begin{array}{c}\text { Tubal factor } \\
\text { control }\end{array}$ \\
\hline $\begin{array}{l}\text { No. oocytes } \\
\text { No. fertilized } \\
\quad \text { oocytes (\%) }\end{array}$ & 233 & 1615 \\
$\begin{array}{c}\text { No. embryos } \\
\text { (\% of fertility) }\end{array}$ & $104(91)$ & $1196(74)$ \\
\hline
\end{tabular}

the birth of healthy children (one singleton, one duplex), two are ongoing in the first and second trimester respectively, and three have resulted in spontaneous abortions. Total failure of fertilisation was seen in four cycles and failed cleavage was observed in one cycle. This occurred in four couples. However two of these couples achieved fertilisation and pregnancies in subsequent cycles. The other two couples are awaiting a second trial. Compared to tubal factor controls the fertilisation rate was lower in the SCI group; however the cleavage rate of fertilised eggs was identical. The lower fertilisation rate is explained by the occurrence of total fertilisation failure in four cases. No serious complications have been encountered in these treatment cycles.

\section{Discussion}

These preliminary data suggest that IVF combined with assisted ejaculation is an effective method for the treatment of infertility due to SCI in males. Our results yield a pregnancy rate per cycle of $30 \%(7 / 23)$ and an ongoing pregnancy rate of $17 \%(4 / 23)$ per cycle. This compares well with the results reported by Toledo et al, ${ }^{12}$ who also studied males with SCI. In combination with IVF this group reported a pregnancy rate of $20 \%(3 / 15)$ per cycle but, when intrauterine insemination was used, only one pregnancy was obtained in 18 cycles. In a recent review a pregnancy rate of only $7.1 \%(56 / 784)$ per cycle was reported when assisted ejaculation was done in combination with intrauterine insemination. ${ }^{13}$ In order to make a proper analysis of the factors determining the probability of success in efforts to achieve pregnancy, the choice of outcome measures is important. IVF offers an opportunity to assess the efficiency of all stages of the process, including fertilisation, early embryonic development and implantation. As experience increases, it will be possible to identify factors contributing to a poor fertilising ability of the recovered sperm. This could be due to recurrent urinary tract infection, method of bladder management, and time since last ejaculation.

The quality of the semen showed considerable variation, ranging from very poor to fair and for this reason one should expect a lower fertilisation rate. However, pregnancy was established in cases in which the recovery of motile sperm was very low, ie $\$ 500.000$ motile sperm in all. In general, the rate of fertilisation is somewhat lower than in the control group of tubal infertility. It should be noted, as mentioned earlier, that on four occasions there was total fertilisation failure, which could suggest that there is a certain subgroup of males with SCI in which more sophisticated methods such as assisted fertilisation with subzonal (SUZI) or intracytoplasmatic (ICSI) sperm injection may be needed. In two out of these four cases fertilisation was achieved in a subsequent cycle. In the study by Toledo et $a l^{12}$ there was a subgroup of patients with very poor sperm quality, which necessitated the use of SUZI.

For most men the fathering of children is the result of a well defined sexual act. The ejaculation is the final link in the sexual function chain: libido-erection-penetration-achievement of climax-ejaculation. For men suffering from SCI this chain of events is broken. Some qualities can be achieved more easily than others. With the 
very good results regarding infertility many such men are becoming aware of the possibility of also pursuing the other androgen dependent parts of the link. This implies that a good fertility programme opens the door to a better sexual life.

In order to develop treatment for couples with infertility due to SCI in the male, it is important to have a well organized team with expertise in the care of SCI, andrology, anaesthesiology, endocrinology, neurology and gynaecology, since this group of couples present specific problems. In our country it can be estimated that approximately 30 couples annually will require assisted ejaculation in combination with IVF due to male post-traumatic SCI subfertility. The limited number of couples would probably best be treated at one to two centres which will then get the necessary experience.

\section{Acknowledgements}

This work was supported in part by grants from the Swedish Medical Research Foundation, the Karolinska Institute and the Spinalis Foundation. Maria Ohlsson and Lena Rogberg assisted in a very professional way in completing the study.

\section{References}

1 Levi R, Hulting C, von Holst H, Ekholm J (1992) A new tool for spinal cord injuries. Läkartidningen (Sweden) 89: 3361-3364.

2 Linsenmeyer TA, Perkash I (1991) Infertility in men with spinal cord injury. Review article. Arch Phys Med Rehabil 72: 747-754.

3 Guttmann L (1949) The effect of prostigmine on the reproductive functions in the spinal man. Proc 4th Int Neurological Congr 2: 69.

4 Brindley GS (1984) The fertility in men with spinal injuries. Paraplegia 22: 337.

5 Seager SW, Savastano JA, Street JW et al (1984) Semen quality and penile erections in normal and chronic spinal non-human primates. J Urol, Part 2, 131: 234A (abstract 522).

6 Denil J, Ohl DA, Menge AC et al (1992) Functional characteristics of sperm obtained by electroejaculation. J Urol 47: 69-72.

7 Bennett CJ, Seager SW, Washer EA, McGuires EJ (1988) Sexual dysfunction and electroejaculation in men with spinal cord injury: Review article. J Urol 139: 453-457.

8 Hultling C, Fredricsson B, Garoff L et al (1994) Assisted ejaculation and IVF. A promising method to treat infertility in male SCIs. Läkartidningen (Sweden) 91: 588-590.

9 Wikland M, Nilsson L, Hansson R et al (1983) Collection of human oocytes by the use of sonography. Fertil Steril 39: 603-608.

10 Lasalle B, Testart J, Renard JP (1985) Human embryo features that influence the success of cryopreservation with the use of 1,2 propandediol. Fertil Steril 44: 645-651.

11 Chapelle PA, Biancart F, Puech AJ, Held JP (1983) Treatment of anejaculation in the total paraplegic by subcutaneous injection of physostigmine. Paraplegia 21: 30-36.

12 Toledo AA, Tucher MJ, Bennett JK (1992) Electroejaculation in combination with in vitro fertilization and gamete micromanupulation for treatment of anejaculatory male infertility. Am J Obstet Gynecol 167: $322-326$.

13 Sönksen J, Biering-Sörensen F (1992) Fertility in men with spinal cord or cauda equina lesions. Semin Neurol 12: 106-114. 